\title{
Rehabilitation in a Cleft Lip and Palate Patient with Oro Nasal Fistula
}

\author{
Dr. Abhinav Gupta ${ }^{1}$, Dr. Saba Afreen ${ }^{2 *}$, Dr. Faraaz M. Ansari ${ }^{3}$
}

${ }^{1}$ Associate Professor, Department of Prosthodontics and Crown and Bridge, Dr. Ziauddin Ahmad Dental College, Aligarh Muslim Uni versity, Aligarh, Uttar Pradesh-202002, India

${ }^{2}$ Junior Resident, Department of Prosthodontics and Crown and Bridge, Dr. Ziauddin Ahmad Dental College, Aligarh Muslim University, Aligarh, Uttar Pradesh -202002, India

${ }^{3}$ Junior Resident, Department of Prosthodontics and Crown and Bridge, Dental College, A.M.U., Aligarh, Uttar Pradesh -202002, India

DOI: 10.36348/SJODR.2019.v04i09.003 | Received: 27.08.2019| Accepted: 04.09.2019| Published: 20.09.2019

*Corresponding author: Dr. Saba Afreen

\section{Abstract}

Cleft lip and palate is a commonly observed congenital maxillofacial defect. Prosthodontics intervention is usually required after incomplete or complete surgical closure of the defect. The final option of treatment mainly depends on the existing clinical condition and patient's acceptance towards the treatment. In this case report, the patient was treated with a fixed partial denture and a removable, flexible gingival epithesis. This clinical report describes a conservative and cost effective method of rehabilitation of such type of defect.

Keywords: Cleft lip and palate, oro nasal fistula, removable gingival epithesis.

Copyright @ 2019: This is an open-access article distributed under the terms of the Creative Commons Attribution license which permits unrestricted use, distribution, and reproduction in any medium for non-commercial use (NonCommercial, or CC-BY-NC) provided the original author and source are credited.

\section{INTRODUCTION}

Cleft lip (CL) is defined as a congenital abnormality of the primary palate (i.e. anterior to the incisive foramen). It may be complete, incomplete or microform, unilateral or bilateral, and may involve a palatal cleft $(C L+P)$.

A cleft palate $(\mathrm{CP})$ is a congenital abnormality of the secondary palate and may be complete or incomplete, unilateral or bilateral, or submucous.

$\mathrm{CL}+\mathrm{P}$ is epidemiologically and aetiologically distinct from isolated CP [1].

Improvement in the facial appearance is important for psychosocial development of patients with cleft lip and palate, who tend to be timid and quiet $[2,3]$. Treatment of orofacial clefts requires multidisciplinary approach which includes multiple surgeries, orthodontic treatment, and complex prosthodontics rehabilitation. These patients present with multiple clinical conditions which further complicates the situation. The patients usually suffer with multiple missing teeth, mobility of premaxilla, malpositioning of anterior teeth as in this case, unfavourable soft tissues and short upper lip [4]. Due to soft tissue deficiency and insufficient bony support, a complete fixed dental prosthesis is usually not possible in most of the cases [5]. So in such cases, an overdenture or overlay type of prosthesis is required to cover the soft and hard tissue defect [6].

Different techniques can be adapted for support of superstructure such as telescopic crowns, swing lock attachment and dual path design suprastructure [7-9].

After surgical closure of the defect fistulas may remain at a rate of $5-38 \%$. This tendency to relapse is due to tension produced by the presence of scarred palatal and lip tissues $[10,11]$.

A second surgical closure may result in complete closure of defect but the choice of undergoing another surgical operation depends on the extent of defect and the desire of patient. With prosthodontics approach, usually a removable prosthesis is recommended for closure of hard and soft tissue defect with fistula [12]. But a removable denture fails to provide the psychological benefit of a fixed prosthesis for the young generation. On the other hand, a fixed prosthesis will not help in maintenance of hygiene and will obliterate the fistula which can further lead to tissue irritation and infection [13].

\section{CASE REPORT}

A nineteen year old female reported to the OPD with the chief complaint of missing front teeth. 
The patient has a history of unilateral cleft lip and palate on the left side which was surgically repaired. The patient had no other relevant medical or family history. She underwent surgery for cleft lip and palate on the left side when she was 1 year old.

Extra oral examination revealed a surgical scar on left side of lip and the patient was reluctant to smile (Fig-1).

Radiographic examination showed radiolucency in 22, 23 region of maxillary alveolar ridge extending upto the nasal cavity suggestive of incompetent closure of oronasal communication (Fig2).

On examination, 22 was missing with alveolar defect in that area, 21 was $180^{\circ}$ rotated with mobility exceeding $1 \mathrm{~mm}$ and the existing oronasal fistula in the vestibule in relation to 22 (Fig $3 \& 4$ ). The patient was not willing for any surgical intervention so the treatment plan was decided with a conservative approach.

Root canal treatment of 21 was done along with restoring the natural form of tooth by sculpting with composite (Fig-5). Tooth preparation of 11, 21 and 23 was done and provisional restoration was given. Once the appearance was confirmed by the patient, final impression was made and a fixed PFM prosthesis was fabricated (Fig-6).

A wax pattern of the gingival epithesis was made and tried in the patient's mouth after cementation of the fixed dental prosthesis (Fig-7). Closure of alveolar defect and fistula was done with a removable, flexible gingival epithesis for maintenance of hygiene and cleansing in the area of fistula to avoid any irritation or infection (Fig-8). Patient was educated about the insertion and removal of the epithesis.

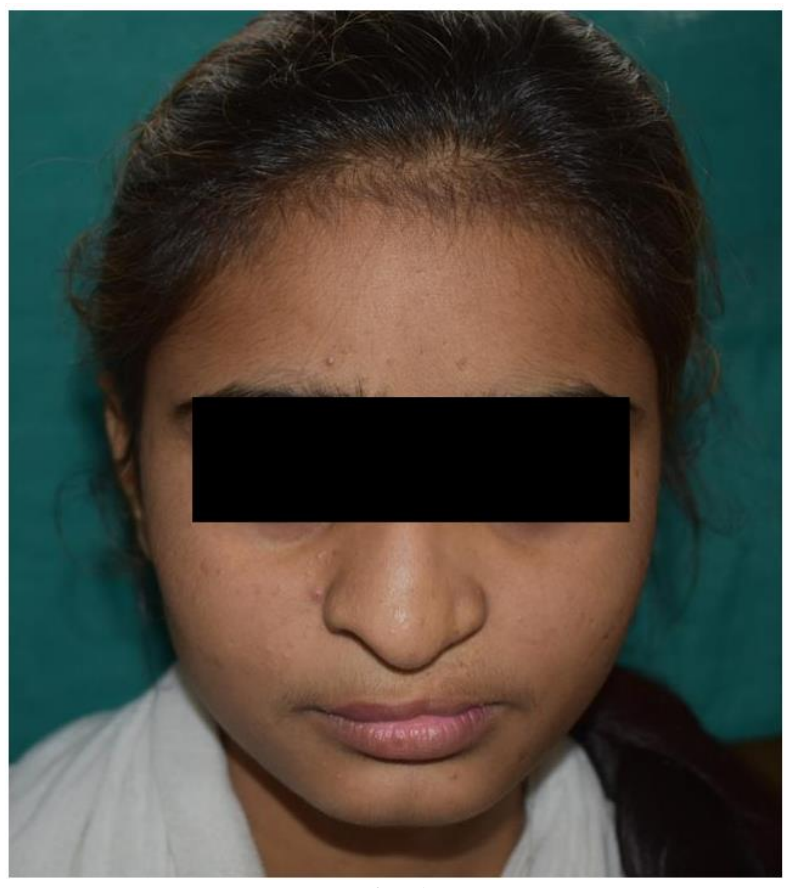

Fig-1:

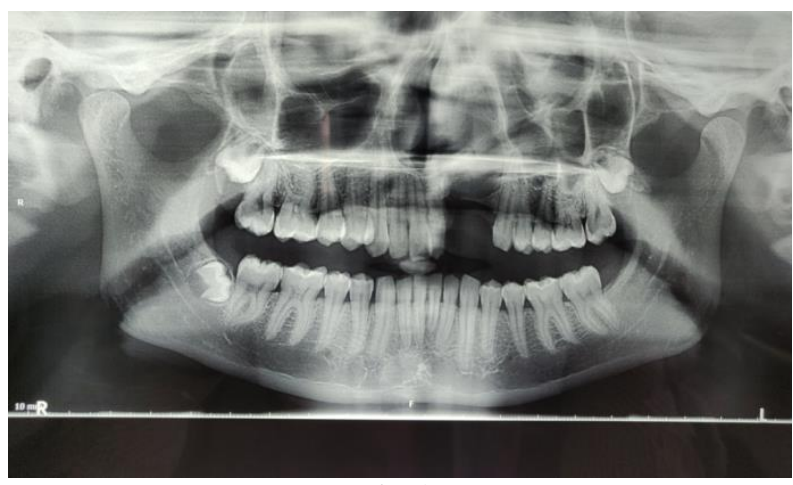

Fig-2:

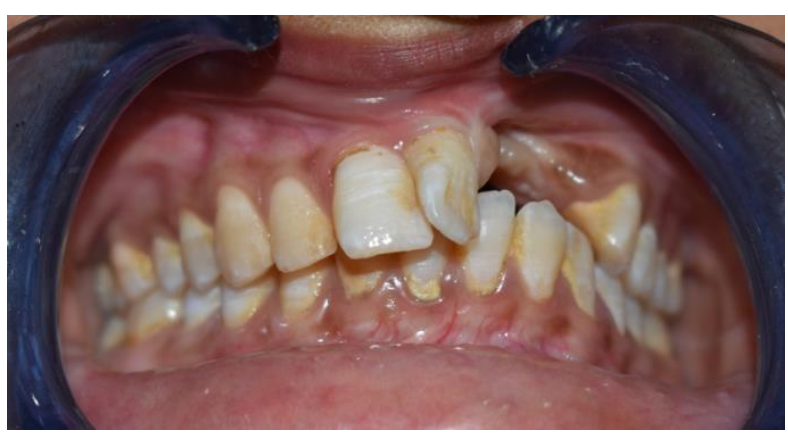

Fig-3: 


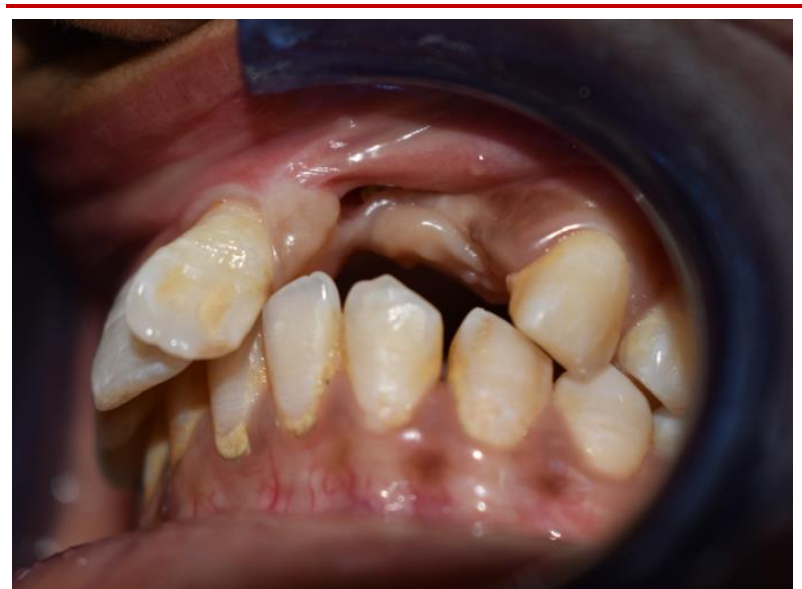

Fig-4:

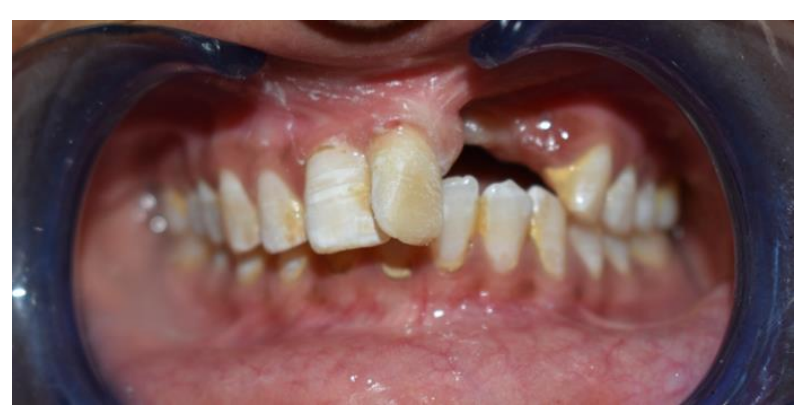

Fig-5:

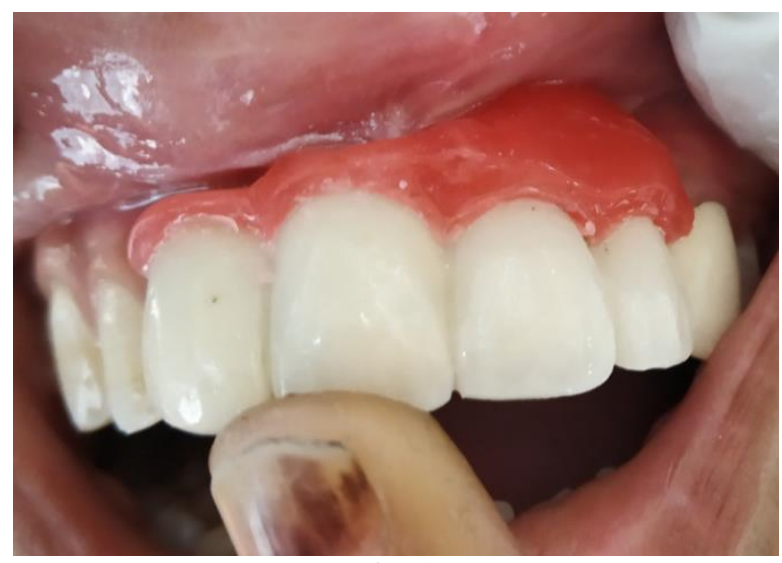

Fig-6:

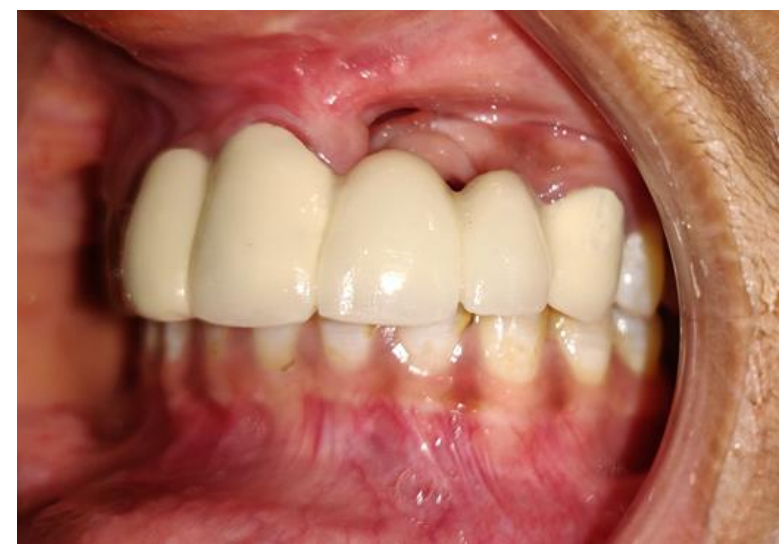

Fig-7:

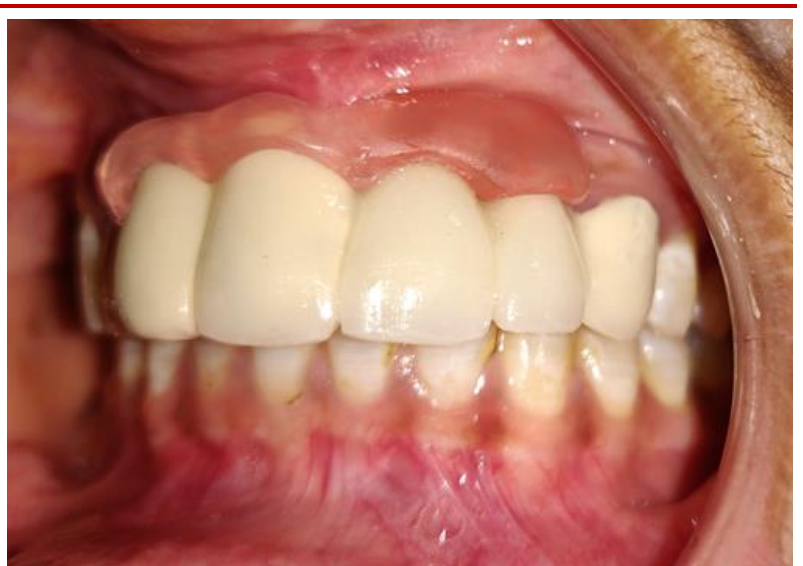

Fig-8:

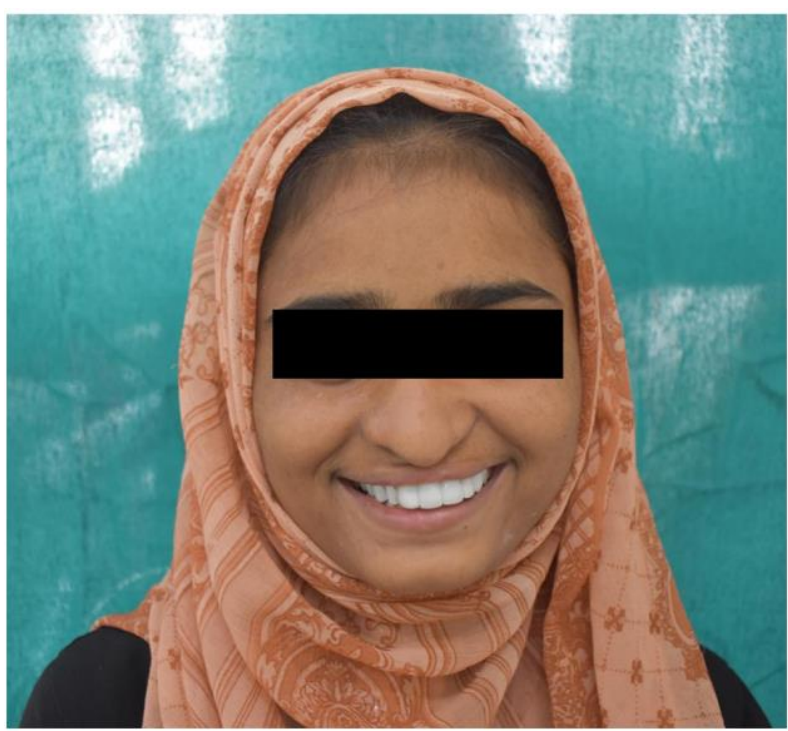

Fig-9:

\section{DISCUSSION}

The factors to be considered for the prosthetic design were:

- The patient did not desire any surgical intervention.

- The patient wanted a fixed dental prosthesis.

- The existing oro nasal fistula demanded proper hygiene maintenance.

So, a cemented 5 unit fixed dental prosthesis was given extending from 11 to 23 and a removable, flexible gingival epithesis concealing and obturating the alveolar defect and fistula, was fabricated.

This design resulted in an acceptable prosthesis with highly improved esthetics. There is good retention of the epithesis. It was easy to place and remove by the patient.

In the present report, a dual approach treatment was given. The existing undercuts were utilized for retention of the epithesis and no additional retentive features were required. This is a reversible treatment, so the patient can be treated later with a definite surgery. 
Also there is preservation of the potential abutment teeth.

Morikawa et al described a similar procedure for a remaining palatal cleft in a young patient. To close the remaining palate cleft, attachment of an O-ring was soldered to the prosthesis and the receptable was embedded in a small acrylic resin prosthesis that was removable for cleaning [14].

Another alternative can be the use of a soft resin obturator like polydimethylsiloxane to restore the missing teeth and close the defect. Drawback of using such materials is the long term maintenance of hygiene [15].

\section{SUMMARY}

This case report describes a prosthesis designed for a remaining fistula in a cleft lip and palate patient. It gives an effective treatment option for such cases. This technique has the advantage of both fixed and removable dental prosthesis, simple fabrication, easy insertion and removal and a moderate cost.

\section{REFERENCES}

1. Goodacre, T., \& Swan, M. C. (2012). Paediatrics and Child Health, 22:4.

2. Peter, J. P., Chinsky, R. R., \& Fisher, M. J. (1975). Sociological aspects of cleft palate adults: IV. Social integration. The Cleft palate journal, 12, 304-310.

3. Kapp-Simon KA, Mcguire DE. Observed social interaction patterns in adolescents with and without craniofacial conditions. The Cleft palatecraniofacial journal. 1997 Sep;34(5):380-384.

4. Bidra, A. S. (2012). Esthetic and functional rehabilitation of a bilateral cleft palate patient with fixed prosthodontic therapy. Journal of Esthetic and Restorative Dentistry, 24(4), 236-244.

5. Acharya, V., \& Brecht, L. E. (2014). Conventional prosthodontic management of partial edentulism with a resilient attachment-retained overdenture in a patient with a cleft lip and palate: a clinical report. The Journal of prosthetic dentistry, 112(2), 117-121.

6. VanBlarcom, C. W. (Ed.). (2005). The glossary of prosthodontic terms. Journal Prosthet Dental; 94:10-92.

7. Balkaya, M. C., Sultan, H., Erdem, S., \& Mutlu, D. (2014). Prosthetic rehabilitation of a patient with a unilateral cleft palate: a clinical report. The Journal of prosthetic dentistry, 111(4), 269-272.

8. Turkyilmaz, I. (2008). Prosthodontic management of patient with cleft lip/palate using maxillary overdenture and swing-lock attachment mechanism. Clinical report. The New York state dental journal, 74(4), 62-64.

9. King, G. E. (1978). Dual-path design for removable partial dentures. The Journal of prosthetic dentistry, 39(4), 392-395.

10. Reid, D. C. (1962). Fistult in the hard palate following cleft palate surgery. British Journal of Plastic Surgery, 15, 377-384.

11. Musgrave, R. H., \& Bremner, J. C. (1960). Complications of cleft palate surgery. Plastic and Reconstructive Surgery, 26(2), 180-189.

12. Immekus, J. E., \& Aramany, M. (1975). A fixedremovable partial denture for cleft-palate patients. Journal of Prosthetic Dentistry, 34(3), 286-291.

13. Gold, H. O., \& Pruzansky, S. (1979). Multipleabutment fixed partial dentures in maxillofacial prosthetics. The Journal of prosthetic dentistry, 41(4), 424-444.

14. Morikawa, M., Toyoda, M., \& Toyoda, S. (1987). Prosthetic management of postsurgical fistulas in patients with cleft lip and palate. Journal of Prosthetic Dentistry, 58(5), 614-616.

15. Taicher, S., \& Sela, M. (1986). Polydimethylsiloxane button obturator for hard palate clefts. The Journal of prosthetic dentistry, 55(1), 82-83. 